\title{
Modelling neodymium isotopes using a general circulation model (FAMOUS): Exploring the role of a benthic flux in unconservative behaviour in paleo records and observations
}

\author{
S. M. ROBINSON ${ }^{1 *}$, R. F. IVANOVIC ${ }^{1}$, L. GREGOIRE $^{1}$
} AND T. VAN DE FLIERDT ${ }^{2}$

${ }^{1}$ Earth \& Environment, University of Leeds, LS2 9JT, UK (correspondance: ee14s2r@leeds.ac.uk) ${ }^{2}$ Imperial College, London, SW7 2AZ, UK

The neodymium isotopic composition $\left(\varepsilon_{\mathrm{Nd}}\right)$ of seawater is extensively used to reconstruct past evolution of ocean circulation. However, uncertainty in quantifying the global ocean $\mathrm{Nd}$ budget and the processes governing the distribution of marine $\varepsilon \mathrm{Nd}$ hinders its application as a circulation tracer. A benthic flux of $\mathrm{Nd}$ has been proposed as a mechanism capable of modifying the $\varepsilon_{\mathrm{Nd}}$ signature of deep and bottom waters. However, a benthic flux has yet to be included in any complex numerical model scheme simulating the global distribution of $\mathrm{Nd}$ isotopes. This highlights an opportunity to devise and test a novel scheme that better deals with the complexity of $\mathrm{Nd}$ cycling in the oceans.

Here, we present the new scheme we are developing, extending previous Nd modelling efforts to constrain mechanisms and cycling of $\mathrm{Nd}$ in the global ocean by simulating $\mathrm{Nd}$ isotopes in a fast-coupled atmosphere-ocean General Circulation Model (FAMOUS). In our new model scheme, the cycling of $\mathrm{Nd}$ isotopes is represented by considering aeolian dust input, dissolved riverine fluxes, boundary exchange, reversible scavenging and for the first time a benthic flux. To do this, we have produced an extensive new compilation of continental margin $\varepsilon \mathrm{Nd}$ boundary/benthic source signature derived from published $\mathrm{Nd}$ isotope measurements. We demonstrate the difference in marine $\varepsilon_{\mathrm{Nd}}$ that is simulated using the new continental margin $\varepsilon_{\text {Nd }}$ data set (presented here) compared to the widely used compilation by Jeandel et al. (2007). 